\title{
Tipe Huruf Prasasti Masjid Girilaya
}

\section{Samrotul Ilmi Albiladiyah}

Keywords: inscription, pulpit, Girilaya mosque, Hamengku Buwono I

\section{How to Cite:}

Albiladiyah, S. I. Tipe Huruf Prasasti Masjid Girilaya. Berkala Arkeologi, 14(2), 191196. https://doi.org/10.30883/jba.v14i2.722

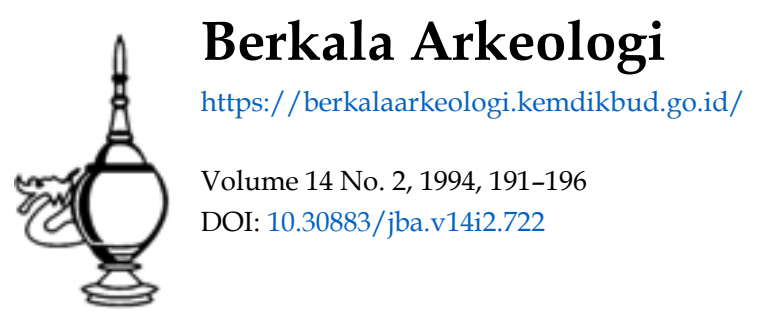

\section{c) (i) (2) (2)}

This work is licensed under a Creative Commons Attribution-NonCommercial-ShareAlike 4.0 International License. 


\title{
TIPE HURUF PRASASTI MASJID GIRILAYA
}

\author{
Samrotul Ilmi Albiladiyah \\ (Balai Kajian Sejarah Dan Nilai Tradisional)
}

I

Girilaya, salah satu dari ke 16 pedukuhan di Kalurahan Wukirsari, Kecamatan Imogiri. Di bukit Girilaya terdapat masjid makam kuna. Pembangunan makam di bukit Girilaya atas prakarsa Sultan Agung, yang pelaksanaannya diserahkan pada pamannya bernama Pangeran Juminah bergelar Panembahan Juminah. Pembangunan makam dimulai tahun 1553 Jawa 16291630 M (De Graaf, 1986 : 299). Pada tahun 1565 Jawa = 1643-1644 M. Panembahan Juminah wafat dan dimakamkan di Girilaya (ibid).

Di bawah makam, terdapat sebuah masjid kuna, atapnya berbentuk tajug, tumpang satu. Kemuncaknya berbentuk mahkota. Masjid tersebut terdiri dari ruang utama, serambi, pawestren dan tempat wudlu. Di dalam masjid terdapat mimbar dan tempat pengimaman (mikrab). Di serambi terdapat meja rendah untuk membaca Al Quran, merupakan peninggalan Susuhunan Paku Buwono $X$ dan Sultan Hamengku Buwana VIII Di masjid, tepatnya di dekat mimbar terdapat

prasasti pendek yang ditulis di atas potongan batu putih berukuran $40 \times 41 \mathrm{~cm}$, tergeletak di antara mimbar dan tembok dinding. Prasasti tersebut ditulis dengan huruf Jawa, bahasa Jawa Selanjutnya prasasti inilah yang akan dikemukakan dalam pertemuan ini.

\section{II}

Ketika diketahui, potongan batu putih berukuran $40 \times 41 \mathrm{~cm}$ itu berada di belakang mimbar. Batu putih tersebut bertuliskan huruf dan bahasa Jawa, keadaannya sudah aus. Juru kunci yang bertugas tidak mengetahui asal letaknya. Melihat ukurannya, batu prasasti tadi mudah dipindah-pindahkan. Yang dapat diketahui dari batu tersebut erat kaitannya dengan pernbanguaán masjid Girilaya. Prasasti yang ditulis di atas batu putih itu terdiri dari 7 baris. Di dalamnya tidak menyebut nama pejabat, orang atau yang memerintahkan. Isinya mengenal pendirian masjid Girilaya, dengan menyebut hari, tanggal, tahun dan dilengkapi sèngkalan,

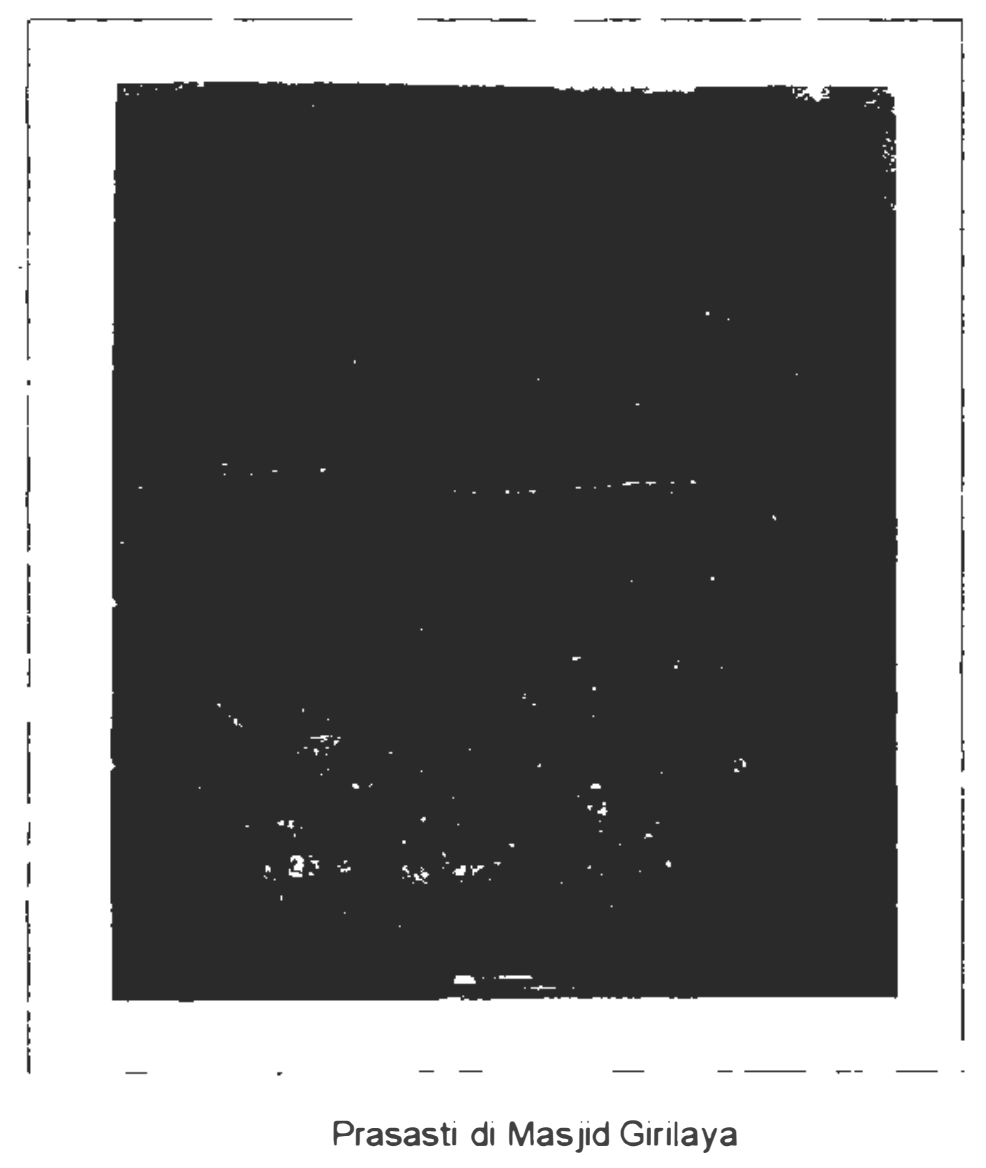




\section{Alih Aksara}

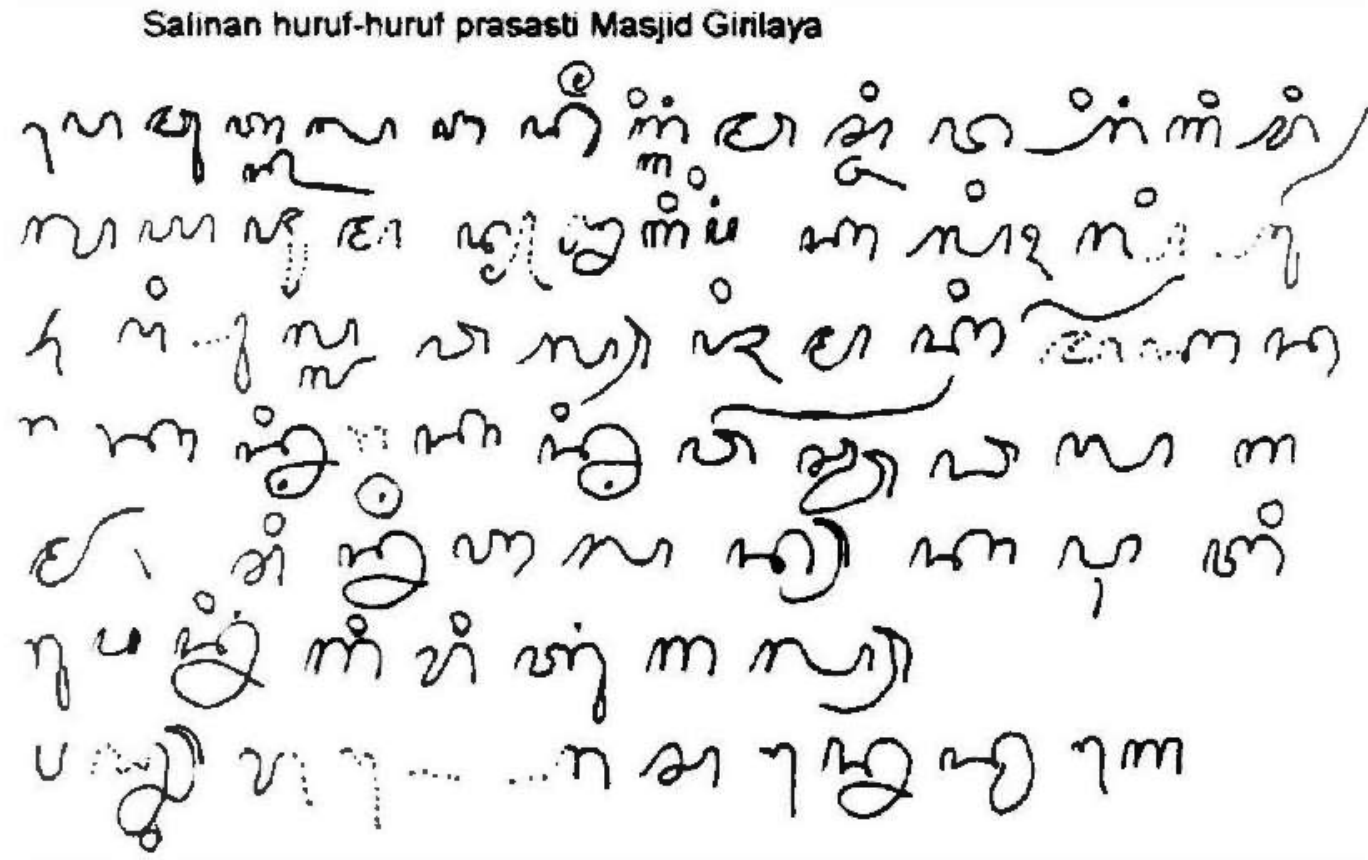

\section{Terjemahan}

1 peringatan waktu berdirinya masjid dı giri,

2. laya han jumat legı tanggal 22 ,

3 bulan rabingulawal tahun jimakir demikianlah,

1 angka tahunnya 171

5. 4 diben tanda sengkaian tahun $k a r(\hat{\mathbf{e}}) \mathrm{t}$,

6 rupaning guri tunggal.

7 menulisnya di hari senin wage

Tipe huruf laws

\begin{tabular}{|c|c|c|c|c|c|c|}
\hline \multicolumn{5}{|c|}{ Prasaso Masjid Girilaya } & \multicolumn{2}{|c|}{ Jawa baru (baku) } \\
\hline \multirow{2}{*}{$\begin{array}{c}\text { abjad / tanda } \\
\text { / anqka }\end{array}$} & \multicolumn{3}{|c|}{ Variasi } & \multirow[t]{2}{*}{ Pasangan } & \multirow{2}{*}{$\begin{array}{c}\text { Huruf / tanda } \\
\text { / anplka }\end{array}$} & \multirow[t]{2}{*}{ Pasangan } \\
\hline & 1 & 2 & 3 & & & \\
\hline ha & $n$ & n & & & nn & n \\
\hline 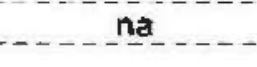 & m & & & & मी & \\
\hline & & & & & ar & $\frac{\sigma}{62}$ \\
\hline ra & 2 & & & & $n$ & \\
\hline $\mathrm{ka}$ & & & & & m & \\
\hline & & & & & & \\
\hline
\end{tabular}




\begin{tabular}{|c|c|c|c|c|c|c|}
\hline da. & $n$ & $m$ & & & $n$ & 6 \\
\hline$\underline{m}$ & $n$ & & & & $\sin$ & $-\leq$ \\
\hline sa. & -8 & - & & & $2 \pi$ & $\begin{array}{r}282 \\
-32 \\
-3\end{array}$ \\
\hline wo & $-n$ & & & & 西 & \\
\hline$-19-$. & n & & & & $m$ & \\
\hline pa & $f m$ & $\bar{u}$ & $u$ & & $R i$ & 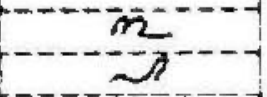 \\
\hline & & & & & & \\
\hline dha & & 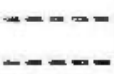 & 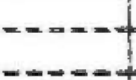 & & I & $\omega^{-}$ \\
\hline ya & 102 & & & & 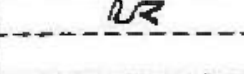 & $\vec{G}$ \\
\hline ye & $\underline{M}$ & $=$ & & $-\frac{1}{2}$ & $\pi N$ & wrd \\
\hline nYa & & & & $(-8)$ & $x$ & of \\
\hline ma- & er & E. & 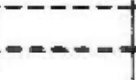 & & N & \\
\hline onga & $w 7$ & & - & & notm & \\
\hline ba & 27 & & & & $n$ & \\
\hline the & & & & & $\pi_{0}$ & \\
\hline nga & $N^{N}$ & & $=-$ & & $\pi 5$ & \\
\hline $\mathrm{h}$ & -7 & $\cdots$ & $\cdots$ & & 2 & \\
\hline wuiu & $\therefore$ & $x \in \ldots$ & & & $\therefore$ & \\
\hline suku & & 4 & 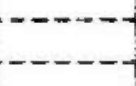 & & IL & \\
\hline tring. & & 1 & 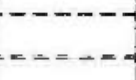 & & 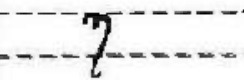 & \\
\hline cacak & & 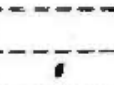 & $\cdots$ & & $\approx$ & \\
\hline tevar & - & $\ldots$ & $\ldots$ & & & \\
\hline pept & 2 & 0 & ล & & & \\
\hline eangku- & 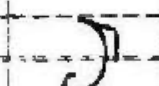 & ... & $\cdots$ & $-\cdots$ & וריו- & . \\
\hline (1) & 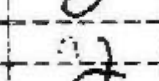 & & & & 87 & \\
\hline 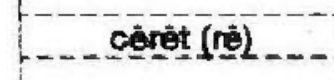 & i) & & & & , & \\
\hline-1 & 25 & $m$ & & & $m$ & \\
\hline 4 & E & $\cdots$ & ]-X] & & $\sqrt{3}$ & 4 \\
\hline$-\overline{7}^{-----}$ & tan & $\cdots$ & $\cdots$ & & 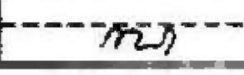 & $+\cdots$ \\
\hline
\end{tabular}


rioe huruf daiam prasastı tergantung pada faktor-faktor yang menyertal. Meskıpun ada perbandirigan prasasti lair yang sezaman, namun apabila penulisnya berbeda, maka berbeda pula yang digoreskannya. Unsur subjektivitas, bahan: peralatan. akan menentukan penyajian Prasasti masjid Girilaya akari berbeda jika dibandingkan dengan prasasti pendek yang ada di kompieks makam Kotagede. Prasasti masjid Girilaya yang berangka tahun 1714 Jawa atau kira-kira tahun १788 \{Stibbe, 1972:408-414) mempunyai variasi huruf sendiri, misalnya hurut-huruf berikut

Huruf ha ditulis dengan tulisan tipis sekali pada kaki depannya, kaki belakang ditulis dengan nyata, tebal, in

pasangan ha bagian depan ditulis dari bawah, $r$

riuruf ra dituils dengan kaki renggang, seperti ra pada pertengahan abad XVI / XVI, $\sqrt{ } 7$ dan Balt. भf ra yang ditulis demik:an terdapat pada baris 1 , Jan baris ke 3 ,

$$
\text { ? }
$$

Huruf ka ditulis biasa tetapi pasangan ka ditulis dibawah dengan akor panjang sepert pada baris 1. . . $2 . .$.

Huruf sa ditulis seperti huruf Jawa Baru baku tetap: lancip di belakang, seperti huruf cá (linat baris ke 4)... (2).

iruruf wa ditulis biasa (JB baku), pasangan wa ditul!s oi hawah huru? dengan cara disamburig dengan Kaki huruf belaking yang ada di atasnya. if

Hurut pa ditulis bervanas! Bans 1 ditulis brasè, baris ô ditulis minñg dengan kaki. Ul baris? dituis ranpa Kaki, sepertı huruf Jawa Kina U.

Huruf ja dituiis dengan kakiı akhir panjang ke Dawah seperti pada baris ke 3. $4:$ Pasangan ja, pada baris 1 ditulis bıasa

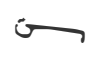

Huruf ya ditulis bıasa (JB Baku) pasangan ya ditulis lancip seperti pada baris ke 4<smiles>C1=CCCCC=C1</smiles>

Huruf nya untuk bunyi nyè ditulis dengan cara membuat huruf na ditamban aasangari mpa di bawah. Cara menulis pasangan, bagian atas lancip sehingga nyè ditulis dengan nnyè seperti baris ke 7

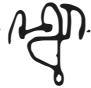

Huruf $\mathbf{m}$ a dituirs iancip di bagian belakang seperti. Er. . baris 1, ada yang ditulis tanpa kaki muka: .. \&A.... pada bans 3 seperti huruf Bali. .... \&

Huruf ga ditulis aengan kaki 4, pasangan go ditulis di bawah huruf dengan model yang sama, $m$ Selain itu hurut ga untuk monulis angka sesudah angka-angka di depan, jika memerlukan angka tersebut. Dengan kata lain inuruf ga untuk menulis angka (?), tetap! bukan angka awa! seperti pada baris ke 4

Huruf $\mathrm{Ga}$ dituils untuk membuat angka (1) awai

$$
\text { r.? }
$$

Huruf nga ditulis dengan cara menyambung terus, I. . ...... Kemungkınan hai ini menyangkust faktor bahan dan untuk mempermudah cara menulisnya.

Tanda suku dituirs tertutup, terus menyambung dengan hurut, misalnya pada baris ke 1, 3, dan 6;

Thing ditulis biasa (JB baku)', tetapi aua yang dituils dengan satu kakı seperti bans pertama. ?

Cécek dituils dengan tanda bitik. Cara membubunkan tanda cecek diletakkan di atas hurut misa!nya pada huruf baris pertama. his. Solairi itu tanda cecók jugo difetakkan dalam lingkaran pasangan bawah. Pada kata [ang] kaning dua kali kata tersebut diulang, tetap dituits

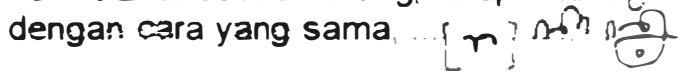

Loyar dituis panjang sekali misainya paua bans 2. 3 dan 4 , 
Pepoir ditulis dengan dua cara: bulatan spira!, baris 1. (C. ... bulatan spiral, bans $5, \ldots$....., bulatan biasa, seperti pacia baris ke 7

Penpitu ditulis lancip bagian atasnya T)

Huruf $n$ mati ditulis dengan pendek, seperti angka 2, (Wignyanj misalnya pada baris ke 2,...?

Huruf pa dengan tanda cèrèt (suara pèpèt) di bawainnya, untuk bunyi ré atau ra mat. Pada baris ke 5 tertulis . $2 \Omega$

Apabila kata yang tertulis pada baris ke 5 tersebut dimaksudkan dengan rerét, maka kemungkınan dan kata reti artınya 1 juga: dijaga. 2. tahu. mengert, jang di dalam sengkałan mempunyai nilai angks 3 (NJS Poenvadarminta, 1939 :529; R Bratakesawa, 1952:92). Jika hal in benar, maka tıdak sesuai dengan angka Jawa yang tertera di dalam prasasti tersebut Namun apabila kata yang dimaksudkan adalah kart = sejahtera, aman. Kata tersebut mempunyai nılai angka 4. 0 dalam baris 5 ini cenderung huruf ré dipakai untuk ra matı (layar). Jika séngkalan yang menggunakan kata karo maka akan sesuai dengan angka tahun yang tertulis pada baris ke $4-5=1714$

Ángka * untuk menyatakan angka 1 dengan 10 huruf, diletakkan di awal deretan angka tahun tersebut. Penulis prasastı menyamakan angka awal dengan 'aksara murda' Ini dapat dilihat pada angka 1 pada baris ke 3 . ditulis dengan huruf ga biasa. $m$.

Angka 4 ditulis kebalikan dengan cara menulis angka 4 (Juwa Baru baku), ekomya ada di bolakang, $\int$...... Angka 4 dalam kaidah Jawa Baru Baku, $\sqrt{3}$

ill

Prasastı masjid Girlaya dibuat sebagaı tanda peringatan berdinnya bangurian masjid yang dimaksud. Kata ngadeging menyatakan pondirian suatu bangunan. Apabila yang dimaksud dalam pembangunan masjid tadi sifatnya memperbaikı, merehabilitası, pada umumnva memaka kata musyokaken. Di dalam prasasti disebutkan bahwa tanggal 22 Rabingulawal tahun Jawa 1714, Jimakir, has Jumat Legi. Tahun Jawa Jimakir, untuk tanggai 1 Syura $=13$ Oktober $1787 \mathrm{M}$ jatun pada har Sabtu Kliwon (Stbbe, 1927:412), sehingga tanggal 22 Rabingulawal adalah tanggal 31 Januan 1788 M, rari Kamis Kliwon. Apabila waktunya soreimaiam, pertitungan hari dalam kalender Jawa telah termasuk hari jumat Legi, sesuai dengan tulisan di dalam prasasti tersebut Sehingga hari jumat legi bertepan dengan tanggal 1 Februari 1788 M., merupakan har pendirian masjid Girilaya yang dimaksud., Pada baris kelima dan keenam tertera tulisan berupa sengkaian. rangkaian kata-kata yang merupakan angke mhur:

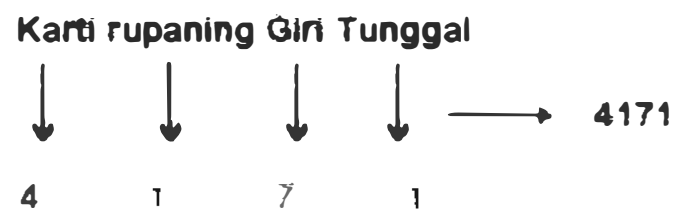

Pada aknir bans disebutkan bahwo penulisannya dilakukan pada hari Senin Wage Jika harı Jumat Legı jatuh pada tanggal 1 Februan $1788 \mathrm{M}$, maka han Senın Wage jatun pada tanggal 4 Februan $1788 \mathrm{M}$. Pada waktu itu yang bertahta di kasultanan Yogyakarta adalah Sultan Hamengku Biwono i (1755-1792). D calam arsip keraton yang ada di Widyabudaya masjid Ginlaya termasuk salah satu masjıd kagungan daforn (milik raja) yang diawası langsung oleh keraton dengan menempatkan abdi dalem jang ditunjuk (Catatan arsıp Kawedanan Pengulon Kraton rogyakarta). Selain itu juga makam yang ada di atas bukit Ginlaya merupakan makam milik keraton. Makam tersebut telah ada pada tahun 1629.1630 M Sehingga apabiia benar masjid didirikari pada tahun 1714 atau $17 \overline{8} 8 \mathrm{M}$. maka ada seiısih waktu puluhan tahun dengan keberadaan makamnya. Akan tetapi jika pembangunan masjid tersebut yang dimaksudkan adalah rehabilitasi, biasanya kata-kata yang diperguna. kan adalan mulyakaken. Muyzcrexen (=memuliakan, melestarikan dalam arti menghormati) dapat diartikan dengan membangun kembali setelah bangunan lama rusak. Dalam kompiek masjid makam, masjid merupakan bangunan kelengkapannya (Soekmono. 1881:83). adapun bangunan utama adalah makam Sebagai bangunan kelangkapan, dapat saja masjid didinkan setelah makam seiesal dibuat. Namun apabila pembuatan masijid tadi terdapat senjang waktu yang sangat iama. ada alasan-alasan kisat yang 
menyertaınya. Untuk mengetahui hal tersebut perlu penelitian lebih lanjut di bidang sejarah kuna

Sebagal penutup uraian pengantar ini, ada beberapa hal yang menarik mengenai prasasti masjid Girilaya;

- Prasastı masjid Girilaya yang ditulis dalam huruf maupun bahasa Jawa Baru, mempunyai variasi tipe huruf tersendiri, masih menunjukkan kekunaan pada beberapa hurufnya

- Darı unsur penanggalan yang ada, menunjukkan bahwa hubungan masjid makam dalam satu kompleks belum tentu berasal dari satu masa. Berdasarkan prasasti yang ada, Masjıd Gırilaya dibangun semasa Sultan Hamengku Buwono I.

\section{KEPUSTAKAAN}

Anonım, tt Arsip Kawedanan Pangulon Keraton Yogyakarta Hadiningrat, Daftar massid dan makam Kagungan Dakem (Arsip dı Widyabudaya)

Bratakesawa, Raden. 1952, Ketrangan Tjandrasengkala,Cetakan || Jakarta:Balai Pustaka

Graaf H.J de.1986, Puncak Kekuasaan Mataram, Politik Ekspansi Sultan Agung (terjemahan dari judul asli De Regering van Sultan Agung, Vorst van Mataram, 1613-1645, en Die van Voorganger Panembahan Sedaing Krapjak 1601-1613), Jakarta: Pustaka Grafitipers dan KITLV

\section{Poerwadarminta, WJS 1939, Baoesastra Djawa, Gronıngen, Batavia: JB.Wolters' Uitgevers-Maatschappij NV}

\section{Soekmono, 1981, Pengantar Sejarah Kebudayaan Indonesia, Jilid III, Yogyakart:: Kanisius}

Stibbe, DG, dkk. 1927, Encyclopaedie van Nederlandsch-Indie, V, cet \| Leiden: 's Gravenhage Martinus Nijhoff E J.Brill. 